\title{
Justo Sierra y la imagen del México moderno en Espańa a principios del siglo $\mathrm{xx}$
}

\author{
Justo Sierra and the Image of Modern Mexico in Spain in the early $20^{\text {th }}$ \\ century
}

Carlos Ramírez Vuelvas

UNIVERSIDAD DE COLIMA, carlosvuelvas@ucol.mx

En el siguiente artículo se revisa la definición de la imagen del México moderno de principios del siglo xx, a partir de la lectura de la opinión pública española en la representación de cuatro momentos de la cultura mexicana: el Congreso Hispanoamericano de 1900; la aparición de los manuales de historia patria; la celebración de las Fiestas del Centenario de la Independencia de México; y la Revolución Mexicana. La interpretación de la opinión pública española sobre dichos eventos muestra la imagen del México moderno que había impulsado el gobierno de Porfirio Díaz a través de las labores intelectuales de personajes como Justo Sierra, quienes buscaban, al mismo tiempo, la definición de la soberanía y la identidad nacional.

Palabras ClaVE: identidad nacional, imaginario, recepción, opinión pública.

This article examines the definition of the image of modern Mexico in the early $20^{\text {th }}$ century based on a reading of public opinion in Spain in relation to four moments of Mexican culture: the Congreso Hispanoamericano of 1900, the appearance of manuals on the patriotic history, the celebration of the Centennial of Mexican Independence, and the Mexican Revolution. The interpretation of public opinion on those events in Spain reveals the image of modern Mexico that the government of Porfirio Díaz had fostered, in part, through the intellectual labors of such personages as Justo Sierra, and which sought, at the same time, to define the country's sovereignty and national identity.

KEYwORDS: national identity, imaginary, reception, public opinion.

Fecha de recepción del artículo: 17 de septiembre de 2014 / Fecha de aprobación: 28 de diciembre de 2014 / Fecha de recepción de la versión final: 3 de febrero de 2015

\section{LIMINARES}

a notable participación de Justo Sierra en la enunciación de la imagen del México moderno a finales del siglo xIx aparece en toda su obra intelectual (literatura, historia, sociología, po- 
lítica), como señalan la mayoría de las investigaciones sobre su pensamiento. ${ }^{1}$ En el ámbito de la política y las relaciones diplomáticas entre naciones soberanas, también prefiguró a México como una nación moderna, de progreso económico, social y cultural; ${ }^{2}$ diseño que tampoco fue homogéneo y que el intelectual modificó según el contexto histórico social en el que fue planteado. Sitiado por los debates intelectuales de la época y por los conflictos económico sociales de México y su región, se trataba de proponer un imaginario de México basado en su progreso y soberanía nacional, que cohesionara las distintas posturas ideológicas y momentos históricos que lo cercaban.

La construcción de la imagen del México moderno (o de las imágenes del México moderno) tuvo como uno de sus principales interlocutores al ámbito de la cultura española, antigua hegemonía dominante del territorio, capital del mundo hispánico y protagonista de las relaciones diplomáticas de México con Europa. Los cambios de esas proyecciones resultan visibles en la opinión pública espańola (me refiero a agentes intelectuales y algunos mediadores, como libros, revistas y periódicos) en cuatro momentos: el Congreso Hispanoamericanos de 1900; la aparición de diversas obras "ob-

${ }^{1}$ Me refiero, en particular, a las emprendidas por Claude Dumas, Justo Sierra y el México de su tiempo, 1848-1912 (México: Universidad Nacional Autónoma de México, 1986); Fausta Gantús, "Justo Sierra: el proyecto de una identidad integradora”, en Construcción de las identidades latinoamericanas. Ensayos de historia intelectual, siglos XIX y XX (México: El Colegio de México, 2004), 110-126; y Aimer Granados García, "Justo Sierra en Madrid. La política mexicana hacia la doctrina Monroe", en Artifices y operadores de la diplomacia mexicana. Siglos XIX y XX (México: Porrúa, Universidad Michoacana de San Nicolás de Hidalgo, Colegio de San Luis, Universidad Nacional Autónoma de México, 2004), 173-190.

${ }^{2}$ Por el uso que a lo largo del siguiente artículo se dará a los conceptos “imagen” e "imaginario", creo pertinente establecer sus definiciones. He preferido esta nomenclatura (en lugar de "idea" o "representación") porque "imagen", definida por Gilbert Durand, se refiere a la representación objetual que da semejanza a una idea; e "imaginario", definido por Cornelius Castoriadis, sería la dimensión de los significados discursivos prácticos y simbólicos que le dan forma y especificidad al comportamiento humano mediante el lenguaje. Además, estas definiciones - "por su espíritu antropológico"- se acercan a la conceptualización de Benedict Anderson de estado-nación moderno como "comunidad imaginada", "una comunidad política imaginada como inherentemente limitada y soberana" desde la perspectiva de la modernidad. Benedict Anderson, Comunidades imaginadas. Reflexiones sobre el origen y la reflexión del nacionalismo (México: Fondo de Cultura Económica, 2011), 23. 
jetivas" sobre la historia de México; la celebración de las fiestas del Centenario de la Independencia de México; y el estallido de la Revolución Mexicana. Cabe mencionar que, además, dichos momentos permitirían la formación de una cronología sobre la evolución de la imagen moderna de México en la opinión pública española. La revisión de la recepción de México en estos contextos construiría un imaginario del país en la opinión pública española.

El proyecto intelectual de Sierra sobre la identidad de México se inserta en uno de los propósitos de Porifirio Díaz en la presidencia del país. Desde su arribo al poder en 1876, Díaz intentó modificar la imagen social de México en el extranjero. Para lograrlo, integró un cuerpo diplomático con intelectuales y políticos destacados, que consolidó un sitio singular en la Embajada de México en España. Tal vez por eso, Díaz dispuso hasta cuatro oficinas diplomáticas en esa geografía: en Lisboa, en Santander, en Barcelona y la sede de la legación en Madrid. Una avanzada diplomática que correspondía a la notable inmigración peninsular (catalanes, gallegos, vascos, asturianos...) a México desde finales del siglo XIx. El proceso de posicionamiento cultural de México en España se intensificó en 1886, al nombrar a Vicente Riva Palacio como embajador (quien amplió el trabajo diplomático emprendido por Ramón Corona en 1874), al que le acompańaron y siguieron otros escritores y poetas, como Juan de Dios Peza, Manuel Payno, Amado Nervo, Francisco A. de Icaza y Justo Sierra, entre otros.

\section{El MÉxico MEdiAdor del CONGRESO HISPANOAMERICANO DE I 900}

El propósito de situar la percepción de un México moderno en la recepción de la opinión pública española comenzó a ser plausible en los primeros ańos del siglo $\mathrm{xx}$. Un ejemplo significativo fue la participación de México en el Congreso Social y Económico Hispanoamericano, organizado por el gobierno español en 1900. En el evento participaron como delegados mexicanos Francisco A. de Icaza, Justo Sierra, Manuel Iturbe y Pablo Macedo, quienes aparecieron retratados el 30 de noviembre en el periódico La Ilustración 
Española y Americana, uno de los rotativos más importantes del momento. Con los abogados también llegó la noticia de que el presidente de México permitía a Federico Gamboa, encargado de negocios en Centroamérica, y a Luis Ricoy, segundo secretario de dicha legación, aceptaran las condecoraciones de comendador y caballero, respectivamente, de la Orden de Carlos III otorgadas por el gobierno de España. ${ }^{3}$

En el programa del Congreso Social e Hispanoamericano, diseñado por Luis de Armińán, se discutieron los asuntos referentes a las relaciones internacionales, comercio de libros y educación. ${ }^{4}$ En los días previos a la inauguración, el presidente del Consejo de Ministros, Práxedes Sagasta, reunió a los congresistas y acordaron que Justo Sierra ocuparía la presidencia honoraria del Congreso, al lado de Francisco Pi y Magrall, José de Echegaray, Criado y Marcelino Menéndez Pelayo. ${ }^{5}$ Los otros delegados mexicanos se situaron en posiciones secundarias dentro del organigrama. Pablo Macedo se presentó a una de las vicepresidencias y Francisco A. de Icaza fungió como secretario. De manera unánime, los representantes de las naciones hispanoamericanas también acordaron que Justo Sierra correspondiera al saludo del ministro de estado durante la inauguración. ${ }^{6}$

En la noche del 10 de noviembre se celebró la sesión inaugural en el salón de la dirección del Palacio de Bibliotecas y Museos, que lució, además de una decoración suntuosa, un lleno total con dos mil asistentes. Los primeros discursos fueron dirigidos por Francisco Silvela y por Práxedes Sagasta. De parte de las delegaciones hispanoamericanas, Justo Sierra "pronunció un elocuentísimo discurso,

${ }^{3}$ Sin firma, "Noticias americanas", La Época, año LII, núm. 18,097, 27 de octubre de $1900,2$.

${ }^{4}$ Juan Gutiérrez Cuadrado y José A. Pascual Rodríguez, "A propósito de las actas del Congreso Literario Hispano-Americano de 1892”, en Edición Facsímil de las Actas del Congreso Literario Hispanoamericano (Madrid: Centro Superior de Investigaciones Científicas, Instituto Cervantes de Madrid, 1992), xx.

${ }^{5}$ Sin firma, "Congreso Hispano-Americano", El Globo, año xxvı, núm. 9,107, 10 de noviembre de $1900,1$.

${ }^{6}$ Claude Dumas, Justo Sierra y el México de su tiempo, 1848-1912, tomo I (México: Universidad Nacional Autónoma de México, 1986), 36-38. 
interrumpido frecuentemente por entusiásticos aplausos". ${ }^{7}$ Sierra aludió a la pérdida de las últimas colonias del imperio espańol en 1898, dibujando un país adolorido: España, "la gran vencida de la moderna historia" ${ }^{8}$ El principal argumento del discurso de Sierra fue definir al nuevo pensamiento de América gestado a partir de las independencias nacionales. En los países de la América libre, decía el orador, se pensaba como latinos más que como hispanos, porque el pensamiento francés generó la modernidad como desarrollo cultural de la raza latina a partir del mestizaje del conocimiento humano. ${ }^{9}$

Mucho se ha dicho y es cierto: no existe la raza latina; pero la familia latina, que comprende grupos de razas distintas, no es un concepto abstracto, es una realidad que todos nos empeñamos en hacer vivir y que resulta por ende, ya que no de la naturaleza, obra de la idea y de la historia, operando por un medio de estupendo alcance: la lengua. ${ }^{10}$

Hubo diversas reacciones al discurso de Sierra, que luego se imprimió en un folleto. Los comentaristas españoles dijeron que "la serenidad del hombre de estado y la independencia del artista, se funden en ellos amablemente, dando nacimiento a un producto que reúne las cualidades y evita los defectos". ${ }^{11}$ De manera oficial, el Congreso Hispanoamericano de 1900 también era visto en Espańa como una reorientación de las relaciones político-comerciales de la Península Ibérica con Hispanoamérica, luego de la pérdida de las últimas colonias americanas. El periódico El Globo señalaba que cuando la Madre Patria se encontraba desconsolada, en alusión a la crisis política y económica por la que atravesaba el país, llegaban "sus hijos más preciados" a reconfortarla: "La desgracia ha trocado

${ }^{7}$ Carlos Luis de Cuenca, "Nuestros grabados", La Ilustración Española y Americana, año XLIV, núm. XLII, 15 de noviembre de 1900, 279-282.

${ }^{8}$ Claude Dumas, Justo Sierra y el México, 17-19.

${ }^{9}$ Justo Sierra, Obras completas del maestro Justo Sierra. Discursos Obras completas del maestro Justo Sierra. Tomo v. Discursos (México: Universidad Nacional Autónoma de México, Coordinación de Humanidades, 1948), 279.

${ }^{10}$ Ibidem.

${ }^{11}$ Claude Dumas, Justo Sierra y el México, 18 y 19. A continuación se consignan y se comentan los periódicos no citados por Dumas. 
nuestra locura en razón. El pesar de nuestra derrota, la vergüenza de nuestra incapacidad, tantos y tantos dolores como han caído sobre este pueblo infeliz, en una hora de suprema congoja, nos devuelve el amor de los nuestros". ${ }^{12}$

Esta reorientación de la diplomacia española debía reconocer la autonomía de las naciones hispanoamericanas para generar lazos económicos que fortalecieran las finanzas nacionales, y era fundamental respetar la introducción del concepto "raza latina", que impulsaban los intelectuales liberales como Justo Sierra. Desde el pensamiento español, la retórica con la que se reconstruían estos lazos aceptaba la soberanía de Hispanoamérica ya no como "una prolongación del alma espańola”, como se pensaba a mediados del siglo XIX, sino como estados con sus propias estructuras de gobierno, como añadía El Globo: "No brilla ya en la América latina con reflejos nuestro existir; no es una prolongación de nuestro espíritu; es otra alma gemela de la nuestra". ${ }^{13}$

Por su parte, el periódico La Época admitía, con modestia, que sus comentarios estaban lejos de formular una argumentación profunda sobre las actividades del Congreso. Consideraba que México era el país que necesitaba un mayor cobijo de los países hispanoamericanos y de Espańa, porque era la última frontera del mundo hispánico y debía enfrentarse, siquiera culturalmente, con Estados Unidos. Por eso admiraba la modernización de México: "los grandes progresos materiales e intelectuales que desde hace veinte ańos verifica la mexicana república; mas sorprende agradablemente esa noble confianza en sus destinos y en su vitalidad que en ocasión tan solemne muestra uno de sus preclaros hijos". ${ }^{14}$

Pero también aparecieron reclamos contra el discurso de Sierra. El periódico El Día expresó su molestia por la dubitación del intelectual mexicano al denominar a las naciones de América lo mismo "hispanoamericanas" que "latinoamericanas". Recriminó las expre-

${ }^{12}$ Sin firma, "Fraternidad", El Globo, año xxvı, núm. 9,107, 10 de noviembre de $1900,1$.

13 Ibidem.

${ }^{14}$ Sin firma, "Congreso hispanoamericano. La sesión inaugural", La Época, año LII, núm. 18,112, 11 de noviembre de 1900, 1. 
siones de Sierra por “independentistas y antiespañolas”, y recordó que sentencias similares habían exacerbado a la prensa hispanoamericana durante las independencias de Cuba y Puerto Rico. ${ }^{15}$ Los grupos católicos fueron más críticos. El semanario La Lectura Dominical lo calificó como una muestra de intereses liberales-masónicos: "Dejando aparte lo pretencioso e hinchado de la forma, hay en el fondo de ese discurso un hervor tan perceptible de masonería, que milagro será que no salga de ahí alguna plancha de las más monumentales que se usan en las logias". ${ }^{16}$

Sierra respondió rápidamente a las críticas. Al terminar el segundo día de actividades del Congreso, los delegados hispanoamericanos y los anfitriones españoles se dirigieron hacia el Café Inglés donde se celebró un encuentro entre periodistas (al que asistieron cerca de 800 comensales) presidido por Manuel Llano y Persi. Antes de concluir la reunión, el escritor mexicano pronunció otro discurso en el que agradeció la gentileza de la prensa espańola. Desmintió que fueran poco amistosas sus palabras de la sesión inaugural, porque "América sigue con interés y simpatía el movimiento regenerador con que esta nación generosa trata de mejorar su condición social y política" ${ }^{17}$ En un momento de la tertulia, también dijo a los comensales que daría "una conferencia en el Ateneo" porque no se pudo "resistir a los ruegos de [Segismundo] Moret y a toda la plana mayor de alli". Los ruegos fueron confirmados hasta por la prensa, que informó el evento en los siguientes términos: "Accediendo a los ruegos de la junta de gobierno del Ateneo de Madrid, el señor don Justo Sierra, representante de México en el Congreso, dará una conferencia cuyo tema será 'Una lección de historia mexicana'” ${ }^{18}$

${ }^{15}$ Bernardino Martín Mínguez, "Congreso iberoamericano. Discurso de don Justo Sierra”, El Día, año xxi, núm. 7,259, 12 de noviembre de 1900, 1. Para otra versión del mismo artículo, véase Sin firma, "Congreso Ibero-Americano", Nuevo Mundo, año viI, núm. 359, 21 de noviembre de 1900, 8 y 9.

${ }^{16}$ Minimus, "Sección de polémica", La Lectura Dominical, año viI, núm. 359, 18 de noviembre de 1900, 728.

${ }^{17}$ Claude Dumas. Justo Sierra y el México, 41.

${ }^{18}$ Sin firma, "Noticias", La Correspondencia de España, año LI, núm. 15,635, 25 de noviembre de $1900,4$. 
Apenas terminaron sus actividades en el Ateneo, Sierra realizó un viaje por Andalucía (tal vez por sugestión de Icaza) para visitar Granada y Sevilla. Después se dirigió a La Coruña, donde el Colegio de Doctores y Licenciados en Filosofías y Letras y en Ciencias obsequió una sesión pública extraordinaria a los delegados mexicanos del Congreso. El acto fue presidido por el decano del colegio, Santiago Mundi, quien lamentó el descuido del Estado hacia la enseñanza pública. El poeta Guillermo Díaz Plaza leyó dos composiciones ensalzando la raza hispánica. Finalmente, Justo Sierra manifestó su gratitud y prometió acrecentar el cariño de México a España, para que a través de la educación pública, como la que gozaba España, se generase la energía para el renacimiento de la raza latina.

\section{LA IMAGEN OBJETIVA DE LA NACIÓN}

Acorde con los discursos de Justo Sierra, que proponía nuevas relaciones entre México y España en el contexto de una revaloración de las estructuras nacionales de ambos estados bajo el concepto de la "raza latina", los intelectuales de las dos orillas comenzaron a registrar formas singulares para comprender sus identidades motivados por la definición de la "raza nacional". La convicción de la panlatinidad, expuesta en el escenario político por discursos como los de Justo Sierra, tenía su equivalente (y tal vez su origen) simbólico en el modernismo hispanoamericano y su apropiación de la literatura francesa visible en México desde los sesenta del siglo xIX, con escritores como Manuel Acuña, Manuel Gutiérrez Nájera o Salvador Díaz Mirón. ${ }^{19}$

Uno de estos documentos con énfasis científico positivista de indagación sobre la raza, fue escrito por Nicolás León con el título Compendio de la historia general de México que apareció en 1901 en Madrid. ${ }^{20}$ Se trata de un detallado estudio no sólo histórico sino

${ }^{19}$ Un ejemplo notable del interés de México por la cultura francesa es la participación de la delegación mexicana en la Exposición de París de 1889, documentada a profundidad por Mauricio Tenorio Trillo, Artilugio de la nación moderna: México en las exposiciones universales, 1880-1930 (México: Fondo de Cultura Económica, 1998).

${ }^{20} \mathrm{El}$ presente artículo no trata de cotejar los contenidos de los manuales de historia nacional de España y de México publicados durante la época, como lo hace María del Rosario Peludo Gómez, "Enemigos de la patria y guerras inevitables: el discurso de la 
arqueológico, geográfico y antropológico del México precolombino y algunas hipótesis sobre las modificaciones que habría sufrido la cultura mexicana a partir de la Conquista. Otro libro que causó polémica fue Carácter de la conquista española en América y en México, según los textos de los historiadores primitivos, de Genaro García, publicado también en 1901 en México. La obra fue ampliamente debatida en la Real Academia de Historia. García exploraba las condiciones ideológicas sobre las que se generó la conquista de América y cómo influyeron en la gestación de un posible "ser americano", a partir de

tres o cuatro sentimientos que destacan con bastante nitidez: la fe en la grandeza futura del país, el pundonor criollo, el culto nacional del coraje, el desprecio de la ley, que han sido los motivos de la voluntad social en esa época [...]. He tratado de marcar la huella del factor económico que influyen de una manera tan activa en todas las manifestaciones de la vida social; en cierto momentos, soporta solo el peso de la Historia. ${ }^{21}$

La principal hipótesis de Genaro García es que la coyuntura provocada por los sentimientos que animaron a la Conquista (el momento histórico en la construcción de la nacionalidad espańola y las condiciones de los pueblos indígenas) derivaría en la gestación peculiar de la personalidad hispanoamericana. García fue uno de los primeros historiadores en utilizar en sus argumentos, referencias a historiadores indígenas. Con base en esos testimonios aseguró que los espańoles no sólo llevaron letras y fe a la Nueva Espańa, también enseñaron la cultura de la violencia. Esta propuesta audaz, y previsiblemente discutible, provocó el resquemor entre los historiadores más ortodoxos de la Real Academia, tanto en México (con Pablo

identidad nacional en México y España (siglo xIx), en Encuentro de Latinoamericanistas Españoles (s.l. España: CеEıв, 2006), 1062-1078. En el caso del presente artículo, sólo se consigna y parafrasea la recepción de aquellos textos que, tratando temas relativos a la historia de la relación México-España, concitaron comentarios en la prensa española.

${ }^{21}$ Genaro García, Carácter de la conquista española en América y en México según los textos de los historiadores primitivos (México: Oficina Tipográfica de la Secretaría de Fomento, 1901), 14. 
Macedo y, más tenue, Francisco Sosa) como en Espańa. El historiador español Cesáreo Fernández Duro consideró que Genaro García ni siquiera hablaba de los pueblos americanos, ya que desconocía la vida de estas poblaciones. En cambio, se explayaba en el pueblo español, al que estudia desde los tiempos de la dominación romana. ${ }^{22}$ También Rafael Altamira leerá cuidadosamente la obra de García, con un juicio que coincide de Fernández Duro: "En ese libro la exactitud histórica ha sido sacrificada a una tesis preconcebida, y que por esto debe ser leído y aprovechado con gran precaución, incluso en los datos ciertos que contiene".

En efecto, a partir de la interpretación histórica empleada por Genaro García se generaron nuevas corrientes de interpretación sobre la llegada de los españoles a América, corrientes teóricas que fueron promovidas con interés especial en las universidades de Estados Unidos. De ahí que se leyera con desconfianza la obra de otros historiadores mexicanos que pertenecían a la "breve corriente literaria”, como la calificó Altamira, generada por la polémica del libro de García, como: Francisco Sosa, que publicó Conquistadores antiguos y modernos (1901), los artículos de Pablo Macedo en la revista La Revista Positiva y varios textos del Boletín Histórico-Mexicano, fundado y dirigido por el mismo Genaro García, donde se abordaron temas relativos a su libro. ${ }^{23}$

La aparición de estos textos, durante un momento peculiar de las relaciones entre México y España, generaba nuevas imágenes sobre la sociedad mexicana. Este movimiento cultural mexicano de afirmación de su identidad nacional expuesto en sus textos históricos, contrastaba con el periodo de depresión por el que cruzaba la sociedad espańola. $\mathrm{Al}$ respecto, desde este ángulo de progreso positivo, se deben revisar otros cuatro eventos culturales concretos sobre la difu-

${ }^{22}$ Cesáreo Fernández Duro, "Carácter de la conquista española en América y en México según los textos de los historiadores primitivos”, Boletín de la Real Academia de la Historia, tomo 39, capítulo v (octubre de 1901): 399-411.

${ }^{23}$ Rafael Altamira, "Literatura histórica hispanoamericana", Nuestro Tiempo, año IV, núm. 42, junio de 1904, 349. Antes de este artículo, Altamira ya había dado a conocer, parcialmente, su discrepancia a la tesis del mexicano en 1902 (Rafael Altamira, "Nota bibliográficas. Carácter de la Conquista Española en América y en México, según los textos de los historiadores primitivos", La Lectura, año II, núm. 17, mayo de 1902, 245-248. 
sión del México nuevo impulsado, principalmente, por intelectuales como Sierra, y posicionado en el campo cultural espańol durante las primeras décadas del siglo $\mathrm{xx}$ :

I. La constitución de la Academia Mexicana de la Historia, que llevaba una decena de años construyéndose en el aire, dará uno de los pasos más importantes (aunque no definitivos, porque le faltarán aún otros diez años de gestión) en 1901, cuando Sierra encabece los nombres de posibles miembros fundadores, acompañado por Ignacio Mariscal, Alfredo Chavero, José María Roa Bárcena, José María Vigil, Francisco del Paso y Troncoso, Francisco Plancarte, entre otros, que llegarán a sesionar en México enviando la minuta de trabajo a Madrid, pero que no consolidarán el proyecto que desaparecerá poco tiempo después.

II. La creación del Ateneo Científico Literario de México, también impulsado por Justo Sierra a su regreso de la experiencia madrileña en 1901. Este primer Ateneo mexicano, presidido por Juan de Dios Peza, sería una presunta corresponsalía con el Ateneo de Madrid. Los medios españoles interpretaron el hecho como un gesto mexicano de filiación por los valores ibéricos en los siguientes términos:

México ha comprendido que no sólo en la esfera de la inteligencia aquellas repúblicas emancipadas deben guardar con la noble madre a quien deben los gérmenes de su civilización y los caracteres de su fisonomía nacional, el vínculo del habla, cuyas artísticas producciones constituyen el símbolo de toda cultura que tiene por fundamento orígenes seculares tan ilustres como lo son los de nuestra literatura nacional. ${ }^{24}$

Además, decía La Ilustración Española y Americana, con este hecho se reconocían los lazos de "sangre" y "raza” que unían a México y a España que, a través de organismos como el Ateneo, asentaba políticamente la unidad biológica entre las dos naciones.

III. Los artículos y reportajes que Amado Nervo publicó en $\mathrm{La}$ Ilustración Artística, de Barcelona, durante casi un año, entre el 27

${ }^{24}$ Juan Pérez de Guzmán, "El Ateneo Científico-Literario de México”, La Ilustración Española y Americana, año XLVI, núm. XXIII, 22 de julio de 1901, 390-391. 
de octubre de 1902 y el 3 de octubre de $1903 .{ }^{25}$ El nombre de Amado Nervo estaba precedido por la recepción de su poesía, mezcla de neomisticismo y modernismo, como la calificaban la mayoría de su comentaristas españoles. En La Ilustración Artística, Nervo creó la columna "Gentes y cosas de México", donde difundió el desarrollo alcanzado por México en áreas de cultura, educación e industria. Su primer texto fue una semblanza de Justo Sierra. ${ }^{26}$ El poeta tenía varios motivos para inaugurar su columna con un retrato del doctor Sierra: en parte porque era un personaje conocido en Espańa, aún recordado por su intervención en el Congreso Hispanoamericano de 1900; en parte porque Sierra mismo personificaba los progresos de México; en parte porque Sierra había gestionado, primero, que esos artículos también se le pagaran a Nervo por cuenta del erario mexicano; y porque había promovido al poeta para que se incorporara al Servicio Exterior Mexicano.

Uno de sus reportajes más interesantes fue el titulado "México nuevo", que apareció acompañado con varias fotografías que demostraban, siquiera visualmente, las afirmaciones de Nervo: "La vieja ciudad colonial, la perla de la corona española en América, la secular metrópoli azteca, llamada por Humboldt en un momento de buen humor 'ciudad de los palacios', aspira ya a merecer este nombre". ${ }^{27}$ En la mayor parte del texto, se destacan los avances urbanos de la capital del país y la construcción de "edificios modernos". Ante el temor del poeta de que el fenómeno urbano desborde la capacidad demográfica de la ciudad, optimista, señala que "la migración europea” resolverá el problema con sus conocimientos.

IV. En este proceso de difusión de las imágenes del nuevo México a principios del siglo xx, el proyecto más importante fue emprendido y coordinado por el mismo Justo Sierra, con la publicación de

${ }^{25}$ Esta serie de artículos-reportajes de Amado Nervo donde difunde el desarrollo de México, será publicada nuevamente en la Revista del Ateneo a partir de 1906 y culminará en 1910.

${ }^{26}$ Amado Nervo, "Gentes y cosas de México. Justo Sierra”, La Ilustración Artística, año XXI, núm. 1,087, 27 de octubre de 1902, 6.

${ }^{27}$ Amado Nervo, "Gentes y cosas de México. México nuevo", La Ilustración Artística, año Xxiı, núm. 1,108, 23 de marzo de 1903, 200-206. 
los dos tomos y tres volúmenes de la enciclopedia México: su evolución social. Sintesis de la historia política, de la organización administrativa y militar y del estado económico de la Federación mexicana, de sus adelantos en el orden intelectual, de su estructura territorial y del desarrollo de su población y de los medios de comunicación nacionales e internacionales, de sus conquistas en el campo industrial, agricola, minero, mercantil, etc. (1900-1902). Como se puede observar, el libro trataba de dar una imagen completa de México de cara al siglo xx. Para ello, Sierra invitó a colaborar a los investigadores y científicos mexicanos más importantes del momento: Agustín Arango, Porfirio Parra (responsable de los apartados dedicados a ciencia y literatura), Ezequiel Chávez, Manuel Sánchez Mármol, Carlos Díaz Dufoó, Bernardo Reyes, Julio Zárate, Jorge Vera Estañol, Gilberto Crespo y Martínez, Miguel Macedo, Pablo Macedo y Genaro Raigosa, quienes escribieron la historia y evolución de distintas áreas de la vida social, cultural, industrial y económica del país.

Para coronar el esfuerzo intelectual dedicado a la obra, Sierra gestionó con el gobierno mexicano que se contratara al editor Santiago Ballescá, ${ }^{28}$ el mismo editor que más de una década atrás había publicado la enciclopedia de historia nacional México a través de los siglos, coordinada por Vicente Riva Palacio. Los Ballescá buscaron la imprenta de Salvat e Hijos para imprimir el millar de ejemplares que les pedía el gobierno de México. Además, contrataron los servicios de la casa de grabados Thomas para diseñar las planchas de la impresión de las tipografías y se encargó el diseño gráfico, incluida la ilustración con imágenes, a artistas como Apeles Mestres, Cabrinety, Cusach Pascó, Pellicer, Riquer y Utrillo, entre otros.

En España, el libro fue recibido con beneplácito porque se reconoció que los escritores participantes eran algunos de los intelectuales más distinguidos de México, y porque se consideraba a este país una de las naciones más importantes de Hispanoamérica. Además, "la numerosísima colonia española que en ella vive, y las muestras de viva simpatía que nuestra patria ha recibido del pueblo mexicano

${ }^{28}$ Laura A. Moya López, "México: su evolución social. 1900-1902. Aspectos teóricos fundamentales”, Sociológica, año 14(41) (septiembre-diciembre de 1999): 127-156. 
en tiempos recientes, redoblan ese interés, que siempre merecería de su yo un cuadro tan completo del estado actual y la historia novísima de México". ${ }^{29}$

\section{La genealogía nacional: las fiestas del Centenario DE LA INDEPENDENCIA}

Con estos antecedentes sobre la imagen y la cultura mexicana, desde finales de 1908, el profesor de la Universidad de Oviedo, Rafael Altamira, organizaba su viaje a Hispanoamérica. ${ }^{30}$ Desde el "año del desastre" de 1898, cuando dio a conocer Psicología del pueblo espanol, Altamira se había familiarizado con temas de la cultura hispanoamericana. Dos años más tarde, en 1900, publicó una miscelánea de aquellos asuntos con el título Cuestiones hispanoamericanas en el que trataba, a grandes líneas, sobre las relaciones culturales de España con Hispanoamérica (educación, política, derecho, lengua...), líneas que debían interpretarse como la continuidad de la gran patria ibérica, fundada, expandida y solventada por la cultura española y sus instituciones educativas, particularmente la Universidad. En este sentido, otras dos preocupaciones sustentarán las ideas de Altamira: mejorar las políticas de las relaciones culturales entre las dos regiones y estudiar la evolución del idioma castellano en América. Las dos acciones estarían dirigidas a defender la cultura española del crecimiento permisivo de Estados Unidos en todo el continente americano, lo que atentaría contra la cultura fundada por España en el siglo XVI. ${ }^{31}$

${ }^{29}$ Hispanus, "Lecturas americanas", La España Moderna, año 15, núm. 179, noviembre de 1903, 144.

${ }^{30}$ Amado Nervo, Obras, tomo II (Madrid: Aguilar, 1967), 211.

31 Tanto Aimer Granados García como Fausta Gantús observan que este tipo de actividades de orden político intelectual formaban parte de diversas estrategias para contrarrestar las propuestas del panamericanismo impulsado por Estados Unidos. De hecho, Granados García propone que el Congreso Hispanoamericano de 1900, "fue convocado pensando en la nueva situación internacional creada por el desenlace de la guerra hispano-cubano-estadounidense. El contundente triunfo de Estados Unidos en el Caribe y en Filipinas terminó con el dominio político español en América, permitiendo que el coloso del norte tomara posiciones que desde el punto de vista comercial, militar y político le permitirían, en corto tiempo, consolidar su expansión en el ámbito de los países de Amé- 
Posteriormente, el ideario de Altamira será conducido hacia el proyecto de la consolidación de la cultura española a través de su estudio histórico desde la perspectiva de una nación generadora de culturas. Su siguiente volumen, España en América (1908), es una extensión de estas ideas. Ahí, Altamira afina sus conceptos y propone que la cultura espańola continuará vigente en la medida que se reproduce en América, compitiendo con las culturas anglosajonas y francesa. ${ }^{32}$

Con ese programa ideológico, Altamira llegó a México el 11 de diciembre de 1909 luego de casi un ańo de viajar por todo el continente americano. ${ }^{33} \mathrm{El} 3$ de marzo de 1910, la revista española Actua-

rica Latina" (Aimer Granados García, Debates sobre España. El hispanoamericanismo en México a fines del siglo XIX (México: El Colegio de México, 2010, 198). Gantús traslada esa situación al pensamiento de Justo Sierra: "El país del norte se presentaba así como un poder al que había que respetar pero en el que no se podía confiar plenamente". Fausta Gantús, "Justo Sierra: el proyecto de una identidad integradora", en Construcción de las identidades latinoamericanas. Ensayos de historia intelectual, siglos XIX y XX (México: El Colegio de México, 2004), 122.

${ }^{32}$ Estas notas apenas esbozan la construcción del pensamiento de Rafael Altamira sobre las relaciones culturales de España con Hispanoamérica, proyecto que el profesor de Oviedo desarrollaría a lo largo de su vida y su carrera intelectual. En 1914, su protagonismo en el desarrollo del americanismo español de principios del siglo xx se extendió a los medios universitarios con la creación de una cátedra de Historia de las instituciones públicas y civiles de América en la Universidad Central (Salvador Bernabéu Albert, "Los americanistas y el pasado de América: tendencias e instituciones en Vísperas de la Guerra Civil", Revista de Indias LxvirI(239) (2007): 256). Como se sabe, Altamira escribió más de dos decenas de libros para abordar el tema del americanismo y su relación con España. Para una lectura más amplia sobre la obra americanista de Altamira véase José Luis Abellán, "Rafael Altamira y el americanismo: un eslabón de la revolución modernista", Rafael Altamira: historia, literatura y derecho. Actas del Congreso Internacional celebrado en la Universidad de Alicante (Alicante: Universidad de Alicante, 2004), 17-21; Pilar Altamira, Diálogos con Rafael Altamira (Murcia: Universidad de Oviedo, Universidad de Murcia, 2009); Gustavo Hernán Prado, Rafael Altamira en América (1909-1910) (Madrid: Consejo Superior de Investigaciones Científicas, 2008); Javier Malagón Barceló, Rafael Altamira y Crevea: el historiador y el hombre (México: Universidad Nacional Autónoma de México, 1986); y Eva María Valero Juan, Rafael Altamira y la reconquista espiritual de América (Alicante: Universidad de Alicante, 2003).

${ }^{33}$ El profesor había divido su estancia mexicana en dos periodos de trabajo: del $12 \mathrm{al}$ 20 de diciembre de 1909 y del 12 de enero al 12 de febrero de 1910, tiempo en el que recorrió las instituciones culturales más importantes del país, además de los estados de Veracruz, Yucatán y Campeche: la Escuela Nacional de Jurisprudencia, la Escuela Nacional Preparatoria, la Escuela de Artes y Oficios, la Escuela Normal de Maestros, el Museo Nacional de Arqueología, Historia y Etnología, el Colegio Nacional de Aboga- 
lidades publicó un reportaje gráfico sobre la estancia de Altamira en México, en el que mostró imágenes y fotografías de distintos edificios modernos del país, y algunos de los paseos que realizó Altamira acompañado por personalidades del mundo intelectual..$^{34}$ Pero en México la prensa no siempre fue condescendiente con la visita del intelectual, porque Altamira era visto como un invitado especial del grupo de Los Científicos (la elite cultural que apoyaba al Porfiriato). Los periódicos antiliberales, conservadores y católicos, no perdieron oportunidad de recriminar el hecho de que el gobierno mexicano invitara a un intelectual "que no es Menéndez Pelayo". Todo ello, porque Altamira llegaba a México como figura de avanzada de los festejos del Centenario de la Independencia de México que se realizarían durante el año de 1910, y cuyo principal promotor era Justo Sierra.

Para los festejos del Centenario, Justo Sierra también invitó a Miguel de Unamuno. En la carta invitación que el intelectual mexicano le escribió al rector de Salamanca, Sierra respondió a los cuestionamientos ya expresados por Unamuno sobre la galofilia del pensamiento mexicano. "En francés se ha educado a la generación a que pertenezco [...] Deficiente y todo, nuestra educación literaria y científica del francés viene, en francés, leí los griegos, sin intentar traducirlos porque nadie nos enseñó el griego", respondió Sierra a Unamuno para luego cuestionarle que si su acusada galofobia no correspondía a una herencia negada del carlismo. ${ }^{35}$ En respuesta, Unamuno no asistió a las fiestas mexicanas.

dos, el Colegio Militar, la Academia Central Mexicana de Jurisprudencia y Legislación, el Ateneo de la Juventud, la Academia Nacional de Ingenieros y Arquitectos, el Casino Español, la Biblioteca Nacional y el Liceo Mexicano, entre otros, donde convivió con intelectuales como Rodolfo Reyes, Roberto A. Esteva, Alfonso Reyes, Jesús Flores Magón, Antonio Caso, Pedro Henríquez Ureña, Agustín Aragón, Telésforo García, Ezequiel A. Chávez, Joaquín D. Casasús, quienes lo acompañaron en algunas de sus conferencias, ya fuera como presentadores o como asistentes. Rafael Altamira, Mi viaje a América (libro de documentos) (Madrid: Librería General de Victoriano Suárez, 1911), 348-350.

${ }^{34}$ Sin firma, "Altamira en México", Actualidades, año III, núm. 107, 3 de marzo de $1910,1$.

${ }^{35}$ Claude Dumas, Justo Sierra, 397-399. 
Rafael Altamira sí participó en la inauguración de la Universidad Nacional, como uno de los principales proyectos de los festejos del Centenario. Ahí, el profesor español se comprometió a impartir cátedra de Historia del Derecho, lo que formalizará un programa de intercambio académico entre México y España. ${ }^{36} \mathrm{El}$ acto implicaba un segundo objetivo: "despertar la confianza en los medios intelectuales hacia la ciencia española, y presentar así a la España nueva”. ${ }^{37}$ Apenas partió Altamira rumbo a Espańa, Sierra se apresuró a escribir una misiva al presidente del Consejo de Ministros de España, Segismundo Moret, para informarle de las exitosas labores del ovetense en México: "El profesor Altamira (iqué nombre tan bien llevado!) ha tratado de temas jurídicos e históricos. El historiador y sabio se han revelado potentemente. Otros Altamiras españoles son los que necesitamos aquî". ${ }^{38}$

Con todo, el entonces embajador de España en México, Bernardo Jacinto Cólogan y Cólogan, matizó los vínculos positivos que significaba el intercambio cultural propiciado por Altamira. Si el profesor había enfatizado su interés por las razas indígenas y la historia de México, en un informe arrebolado de hispanismo, el embajador consideraba que "en ello no está la civilización y promesa del porvenir", sino en la "convivencia con una Espańa culta y vigorosa" para fortalecer su propio ser y su sentimiento de la patria. ${ }^{39} \mathrm{De}$ acuerdo a esta versión oficial, en el ánimo del gobierno español aún permanecía el deseo de impulsar una cultura hispánica que, desde esta perspectiva, podría dedicarse al estudio del pasado precolombino de Hispanoamérica.

Eran los días previos a la celebración del Centenario de la Independencia de México, y eran las vísperas de la Revolución. Durante el mes de septiembre de 1910, las actividades deslucidas del primer evento vislumbraron el horizonte fáustico del segundo. De cualquier

${ }^{36}$ Rafael Altamira, Mi viaje, 351.

${ }^{37}$ Josefina Mac Gregor, México y España: del Porfiriato a la Revolución (México: Instituto Nacional de Estudios Históricos de la Revolución Mexicana, Secretaría de Gobernación, 1992), 73.

${ }^{38}$ Ibidem, p. 76.

${ }^{39}$ Archivo General del Ministerio de Asuntos Exteriores y Cooperación. P-58-2 448. 
forma, el gobierno español envió una comitiva especial para el festejo nombrando embajador extraordinario al marqués de Polavieja, Camilio García del Polavieja y del Castillo, cuya madre era mexicana. ${ }^{40}$ Porfirio Díaz, aún en la silla presidencial, celebró la inauguración oficial de las fiestas en la Ciudad de México, y enfatizó la presencia y el apoyo del gobierno espańol. ${ }^{41}$ En su discurso, el estadista conservó el prurito de dirigirse a España como la madre patria y se vanaglorió de su pasado español: "Si España ufánase de habernos dado vida, México se enorgullece de reconocerlo y proclamarlo". ${ }^{42}$ Dos actos coronaron la participación política de España en las fiestas, la entrega del uniforme militar de José María Morelos y Pavón y la entrega de la medalla Carlos III a Porfirio Díaz. México correspondió colocando una imagen de Carlos III en el Palacio Nacional, y erigiendo un monumento a Isabel la Católica en el bosque de Chapultepec. ${ }^{43}$

\section{LA IMAGEN MEXICANA DEL CAOS, OTRA VEZ}

Desde mediados de 1910 se habían intensificado las protestas contra el gobierno de Díaz en todo el territorio mexicano, y la fecha fatal del Porfiriato se aproximaba. En Madrid, durante el verano, el embaja-

${ }^{40}$ A la distancia, Blanca de los Ríos se sumó a las festividades no sólo mexicanas, sino de la independencia de todas las naciones hispanoamericanas, cuando el 10 de febrero de 1910 leyó su conferencia “Afirmación de la raza” en el Ateneo de Madrid, que posteriormente sería editada por la misma institución. Sobre el concepto de hispanidad de Blanca de los Ríos véase: Manuel Guerrero Cabrera, "El americanismo de Blanca de los Ríos (breves notas bibliográficas)”, Saigón, núm. 1, 34-35.

${ }^{41}$ J. Mac Gregor, México y España, 81.

${ }^{42}$ Ibidem, p. 82.

${ }^{43}$ Las fiestas mexicanas también fueron motivo de exotismo entre los círculos intelectuales de Madrid. El periodista Nicolás Rivero publicó en el libro Recuerdos de México, 1910 (1911) la crónica de su estancia en aquel país, al que asistió para informar en Espańa sobre las fiestas del Centenario de la Independencia. "Pero lo que principalmente hablaremos en estas páginas -escribió el periodista en su prólogo-, escritas entre el tráfago y las nerviosidades de la lucha diaria - no lo olviden nuestros lectores- será de la naturaleza mexicana, de sus montańas imponentes; de sus valles fertilísimos; de sus habitantes blancos, mestizos e indios puros; de las colonias extranjeras, y con más cariño, claro está, de la espańola; de las costumbres y los gustos rarísimos de aquel país de climas tan variados, que en pocas horas se puede pasar en él de la tierra caliente a la región de las nieves eternas”. Nicolás Rivero, Recuerdos de México, 1910 (Habana: Imprenta y papelería de Rambla y Bouza, 1911), x. 
dor Juan Antonio Beistegui debió declarar a la prensa que en su país la vida cotidiana se mantenía tranquila y que en la provincia sureńa de Yucatán sí hubo un alzamiento de "indios mayos", pero que ya estaba controlado. "El resto de la república reina completa tranquilidad", cerraba su escueto comunicado. ${ }^{44}$ Todavía en la primera quincena de noviembre, el embajador de México en Europa, Juan Sánchez Azcona difundió largas entrevistas en los periódicos de la Villa y Corte para desmentir que hubiera una revolución, sino "un periodo de convulsión social" en el que el país se ajustaba para continuar en la senda "de la justicia y el progreso". Además, señaló que las noticias distorsionadas que presentaban un México bárbaro en la prensa europea eran producto de las agencias informativas estadounidenses.

Pedimos solamente, en nombre de la verdad que se nos juzgue sin apasionamiento, que se considere nuestra situación, que se nos compare con otros ejemplos idénticos de la historia humana y que se nos dé derecho a rechazar la opinión de que somos el "Méjico bárbaro" de que habla el sajón. Fuimos, hemos sido, el "México revolucionario". Nuestra situación presente es el resultado ineludible de antecedentes sociológicos. Combatimos por ascender. Tengo la plena seguridad de que estamos logrando nuestro propósito de mejoramiento. Los medios han tenido, por el ímpetu de las circunstancias, que ser rudos. ${ }^{45}$

Juan Sánchez Azcona era un diplomático conocido, principalmente, en Italia, en Francia y en España, y debía negociar con estos países el apoyo a Porfirio Díaz. Pero cuando el viejo oligarca oaxaqueño perdió el rumbo de México, o perdió su rumbo en México y se exilió en Europa, Sánchez Azcona comenzó a realizar operativos políticos a favor de Francisco I. Madero, claro triunfador de las elecciones posteriores al inicio de la Revolución Mexicana. Amado Ner-

${ }^{44}$ Sin firma, "Notas políticas", La Época, año LXII, núm. 21,420, 11 de junio de 1910 , 3. Cabe aclarar que se trata de la deportación de indígenas mayos y yaquis (llevados de Sonora a Yucatán) durante el régimen porfirista, como parte de las llamadas Guerras del Yaqui que desconocían los territorios comunales de los indígenas.

${ }^{45}$ Juan Sánchez Azcona, "El ministro de México en Europa expone a los lectores de El Liberal la verdadera situación de su país”, El Liberal, año xxxvin, núm. 18,612, 16 de noviembre de 1910, 1. 
vo fue uno de los primeros escritores diplomáticos en presentarse a las órdenes de Sánchez Azcona, en términos de "la Revolución, dirigida por intelectuales, había de ayudar a los intelectuales" ${ }^{46}$

Nervo, en su calidad de encargado de negocios de México, envió una carta a la redacción de los periódicos señalando que la revuelta estaba conformada por " 25 revoltosos", que ya habían sido controlados por el ejército federal mexicano. ${ }^{47} \mathrm{~A}$ partir de entonces, al poeta redirigió a la prensa española los informes que las autoridades oficiales le enviaban desde México sobre los acontecimientos de la Revolución. ${ }^{48}$ Nervo se sentía "solo en la Legación mientras llega el nuevo Ministro (probablemente Justo Sierra), tengo que desplegar durante todo el día una actividad continua" ${ }^{49}$ Por su parte, el ministro de España en México, Bernado Cólogan y Cólogan también informaba de la situación en el país. ${ }^{50}$ En su opinión, la revuelta sería momentánea y sería controlada inmediatamente. ${ }^{51}$

Probablemente porque muchas industrias y empresarios españoles habían crecido en México durante el Porfirato, en España existía una profunda afinidad hacia el general Díaz, simpatía que se acrecentó gracias a las labores de sus intelectuales diplomáticos en la Villa y Corte. De ahí que periodistas como Julio Sesto afirmara, "no sólo tirano. Era enérgico porque necesitaba serlo; pero era también sabio, era patriota y era trabajador". ${ }^{52}$ El periodista opinó que Porfi-

${ }^{46}$ Amado Nervo, Obras, tomo II, 1,157.

${ }^{47}$ Amado Nervo, "Lo de Puebla", La Correspondencia de España, año LXI, núm. 19,276, 21 de noviembre de 1910, 5. También véase Sin firma, "Los desórdenes de México", El Liberal, año xxxiı, núm. 11,343, 21 de noviembre de 1910, 2.

${ }^{48}$ Sin firma, "La situación de México", El Liberal, año xxxıx, núm. 13,568, 7 de enero de 1911, 1.

${ }^{49}$ Amado Nervo, Obras, tomo II, 1,159.

${ }^{50}$ La constante intervención de Cólogan y Cólogan en la política mexicana provocará un recrudecimiento de "la cuestión antiespañola" en México, donde se le acusó de participar, como coautor intelectual, en el asesinato del presidente Francisco I. Madero en 1913. Almudena Delgado Larios, "Entre el miedo y la fascinación: la Revolución mexicana en la prensa española”, Revista de Occidente (358) (noviembre de 2010): 27-48.

${ }^{51}$ Josefina Mac Gregor, "México y Espańa: de la representación diplomática oficial a los agentes confidenciales, 1910-1915", Historia Mexicana, año L, L(2) (octubre-diciembre 2000): 309-330.

52 Julio Sesto, “¿Cómo está México?”, Nuevo Mundo, año xvııı, núm. 919, 17 de agosto de 1911, 3 . 
rio Díaz, el gran fundador del México moderno, había terminado por no comprender su obra que, en un progreso constante, superó al patriarca. En su confusión, el general Díaz había "despechado” a las figuras que representaban la pujanza de ese México moderno y, en respuesta, la fortaleza de los jóvenes que forjaban esa nueva patria, terminaron por destronarlo.

En términos generales, la prensa espańola mostró una visión exotista sobre lo acontecido en México, opiniones de igual forma divididas por las tendencias ideológicas dominantes. ${ }^{53}$ Por un lado, la prensa monárquica señalaba el caos, la anarquía y la decadencia mexicana, con la caída de Porfirio Díaz y la irrupción revolucionaria, y dicha prensa se caracterizó "por su etnofobia hacia los indígenas, su eurocentrismo cultural y su aversión al imperialismo de Estados Unidos en México"; ${ }^{44}$ en tanto que para la prensa obrero anarquista, México se había convertido en el modelo de revolución progresista, "servía como modelo y, además, permitía discernir quiénes eran los auténticos reformistas en España". ${ }^{5}$

Sin embargo, ambas tendencias coincidían al reprobar los hechos que afectaban "a las personas o propiedades de los españoles en México". ${ }^{56}$ La confusión sobre los sucesos de México empañados por los lentes ideológicos con los que observaban los medios de comunicación, expandía la imagen amorfa de la realidad del país,

${ }^{53}$ Uno de los informantes españoles más activos sobre el acontecer de México durante 1910 fue el periodista Vicente Gay, quien cubrió para La España Moderna las fiestas del Centenario. Sus reportes se iniciaron con la muerte de Juan de Dios Peza, siguieron con la creación de la Universidad Nacional, luego recordó la Independencia de México y, finalmente, poco antes de salir del país, habló sobre la Revolución Mexicana. Véanse las siguientes colaboraciones, todas firmadas por Vicente Gay y publicadas en La España Moderna: "La América moderna”, año xxII, núm. 263, noviembre de 1910, 155-176; "La América moderna”, año xxiıI, núm. 272, agosto de 1911, 130-156; "La América moderna”, año xxııI, núm. 274, octubre de 1911, 158-176; "La América moderna”, año xxiII, núm. 276, diciembre de 1911, 105-122; "La América moderna”, año xxiv, núm. 282, junio de 1912, 148-172; y “La América moderna”, año xxıv, núm. 285, septiembre de 1912, 156-172.

${ }^{54}$ Joaquín Beltrán Dengra, La Revolución Mexicana a través de la prensa española (1911-1924) (México: Consejo para la Cultura y las Artes de Nuevo León, 2008), 224.

${ }^{55}$ Almudena Delgado Larios, "Entre el miedo y la fascinación: la Revolución mexicana en la prensa española”, Revista de Occidente (358) (noviembre de 2010): 27-48.

${ }^{56}$ J. Beltrán Dengra, La Revolución Mexicana, 77. 
percepción que se propagó rápidamente por el panorama internacional. ${ }^{57}$ En sus cartas íntimas, Nervo compartía la misma sensación de incertidumbre: "La situación en México es, en efecto, angustiosa. Ojalá que no nos toque a nosotros ver la amputación de la nacionalidad. Todos los mexicanos debíamos apoyar al gobierno constituido, con el solo noble fin de salvar a la patria..., ipero hay un desencadenamiento de ambiciones!"58

Con ello, la imagen de México se verá modificada nuevamente, por lo menos hasta que termine el periodo revolucionario. Los avances tecnológicos y culturales del país, que los agentes intelectuales habían difundido en la opinión pública y el campo intelectual español, proponían una imagen mexicana de estabilidad y progreso, la cual fue suspendida con la irrupción de la Revolución. Posteriormente, la prensa también destacará la evolución democrática del país, planteamiento que expresarán otros intelectuales mexicanos en Europa.

\section{Conclusiones: el imaginario del México moderno}

En 1900, Justo Sierra ensayó sus primeras definiciones del México moderno frente al público español. Ante la disyuntiva histórica del momento (la pérdida de las colonias españolas por el intervencionismo estadounidense), la defensa de su filiación ideológica (el reconocimiento de Estados Unidos como la gran nación del liberalismo), la aplicación de los métodos de historia positivista (el análisis de la identidad nacional a partir de la categoría "raza humana") y la definición de la soberanía nacional, Sierra prefirió ampliar el concepto de "raza latina" para mediar entre la historia, la ciencia y la política. México formaba parte, como Espańa y Francia, de la cultura latina

${ }^{57}$ A. Delgado Larios, "Entre el miedo", 29.

${ }^{58}$ Amado Nervo, Obras, tomo II, 1,160. Aún así, en la Legación de México en Espańa, Juan Antonio Béistegui continuaba ofreciendo banquetes y recepciones cuyos programas eran clausurados por la declamatoria lírica de Amado Nervo. Monte Cristo, "De sociedad", El Imparcial, año xuIv, núm. 15,438, 1 de marzo de 1910, 3; también véase Sin firma, "Noticias de sociedad", La Época, ańo LXII, núm. 21,418, 9 de junio de 1910, 1; y Sin firma, "De sociedad”, El Liberal, año xxxII, núm. 11,178, 9 de junio de $1910,3$. 
(cuna del liberalismo) que se oponía culturalmente a los anglosajones. De esta manera, México era soberano en el ámbito político; y en términos culturales, igual a España, respetaba la representación ideológica de Estados Unidos como máximo exponente de la historia del liberalismo.

El positivismo, como pensamiento científico de corte liberal y francés, provocó una revisión de la historia nacional a partir del cuestionamiento de las fuentes históricas de las primeras historias de México como territorio y la investigación de las "razas originarias de México". Ello propuso una imagen mexicana objetiva, hipótesis científica que para su validez se acompañó de la consolidación de otras instituciones culturales del país. Casi al mismo tiempo, en concordancia con el momento histórico, las Fiestas del Centenario de la Independencia de México fueron motivo para proyectar a la opinión pública española, la plena soberanía del país a pesar del inminente estallido de la Revolución Mexicana.

Todavía en 1910, Sierra arropó su propuesta de la soberanía del México moderno, al enfatizar en la fijación de los límites de la cultura latina en México y defender su territorio nacional (en el plano de la cultura patria) de la posible invasión de los Estados Unidos ante el momento de inestabilidad política por el que atravesaba el país. No obstante, ninguno de estos esfuerzos pudieron contener la aparición de la imagen del México caótico que se suscitó en la opinión pública española luego del estallido de la Revolución. Todo el entramado intelectual mexicano (escritores, diplomáticos y medios de comunicación) que trabajaba a favor de la proyección del México moderno en la opinión pública de Espańa, se vio alterado por el estallido social que derrumbó al sistema político de Porfirio Díaz. A pesar de las simpatías generadas por el gobierno mexicano en la prensa española, y a pesar de que la mayoría de las voces intelectuales españolas simpatizaban a favor del restablecimiento de la paz y el orden en el país (al que ya reconocían como un Estado soberano) la imagen del México moderno, a la manera de holograma, fue sobrepuesta por la del caos revolucionario, según el ángulo ideológico (prensa liberal contra prensa monárquica) desde el que fueran vistas la noticias sobre el país. 


\section{ARCHIVO}

Archivo General del Ministerio de Asuntos Exteriores y Cooperación. Gobierno de España. Expediente, P-58-2 448.

BibliografíA

Altamira, Rafael. Mi viaje a América (libro de documentos). Madrid: Librería General de Victoriano Suárez, 1911.

. "Literatura histórica hispanoamericana", Nuestro Tiempo, año IV, núm. 42, junio de 1904, 349.

. "Notas bibliográficas. Carácter de la Conquista Española en América y en México, según los textos de los historiadores primitivos", La Lectura, año II, núm. 17, mayo de 1902, 245248.

Anderson, Benedict. Comunidades imaginadas. Reflexiones sobre el origen y la difusión del nacionalismo. México: Fondo de Cultura Económica, 2011.

Beltrán Dengra, Joaquín. La Revolución Mexicana a través de la prensa española (1911-1924). México: Consejo para la Cultura y las Artes de Nuevo León, 2008, 224.

Bernabéu Albert, Salvador. "Los americanistas y el pasado de América: tendencias e instituciones en Vísperas de la Guerra Civil". Revista de Indias LXVIII(239) (2007): 256.

Castoriadis, Cornelius. La institución imaginaria de la sociedad. Buenos Aires: Tusquets Editores, 1993.

Delgado Larios, Almudena. "Entre el miedo y la fascinación: la Revolución mexicana en la prensa española”. Revista de Occidente (358) (noviembre de 2010): 27-48.

. La revolución mexicana vista desde España, 1910-1931.

México: Publicaciones Cruz O., 2010.

"Exotismo, afán de aventuras e hispanoamericanismo: La ruta de Hernán Cortés de José Segarra y Joaquín Juliá, entre la hazaña personal y la propaganda oficial. Versión completa. Anuario de Estudios Americanos, tomo LII(2) (1996): 285-309. . La Revolución Mexicana en la España de Alfonso XII (1910- 
1931). Salamanca: Servicio de Publicaciones de la Consejería de Cultura y Turismo, Junta de Castilla y León, 1993.

Dumas Claude. Justo Sierra y el México de su tiempo, 1848-1912. Tomo I. México: Universidad Nacional Autónoma de México, 1986.

Durand, Gilbert. Las estructuras antropológicas del imaginario. México: Fondo de Cultura Económica, 2004.

Escuela de Estudios HispanoAmericanos. La comunidad iberoamericana de naciones. XI Encuentro de Latinoamericanistas Españoles. Santander: CEIIB, 2006, 1,347.

Fernández Duro, Cesáreo. "Carácter de la conquista española en América y en México según los textos de los historiadores primitivos", Boletín de la Real Academia de la Historia, tomo 39, capítulo v (octubre de 1901): 399-411.

GANTús, Fausta. "Justo Sierra: el proyecto de una identidad integradora". En Construcción de las identidades latinoamericanas. Ensayos de historia intelectual, siglos XIX y XX. México: El Colegio de México, 2004.

García, Genaro. Carácter de la conquista española en América y en México según los textos de los historiadores primitivos. México: Oficina Tipográfica de la Secretaría de Fomento, 1901.

Granados García, Aimer. Debates sobre España. El hispanoamericanismo en México a finales del siglo XIX. México: El Colegio de México, Universidad Autónoma Metropolitana, 2010, 110-126.

- "Justo Sierra en Madrid; la política mexicana hacia la doctrina Monroe". Artifices y operadores de la Diplomacia Mexicana siglos XIX y XX. México: Porrúa, Universidad Michoacana de San Nicolás de Hidalgo, Universidad Nacional Autónoma de México, 2004, 173-190.

. "El Congreso Hispanoamericano de 1900. Unión espiritual y relaciones comerciales entre España y América Latina”. México y España en el siglo XIX. Diplomacia, relaciones triangulares e imaginarios sociales. México: Universidad Michoacana de San Nicolás de Hidalgo, Instituto de Investigaciones Históricas, Instituto Tecnológico Autónomo de México, 2003, 267-283. 
Granados García, Aimer y Carlos Marichal, comps. Construcción de identidades latinoamericanas. Ensayos de historia intelectual, siglos XIX y XX. México: El Colegio de México, 2004.

Guerrero Cabrera, Manuel. "El americanismo de Blanca de los Ríos (breves notas bibliográficas)”, Saigón, núm. 1, 34-35.

Gutiérrez Cuadrado, Juan y José A. Pascual Rodríguez. “A propósito de las actas del Congreso Literario Hispano-Americano de 1892”. Edición Facsimil de las Actas del Congreso Literario Hispanoamericano. Madrid: Centro Superior de Investigaciones Científicas-Instituto Cervantes de Madrid, 1992, xx.

Hispanus. "Lecturas americanas". La España Moderna, año 15, núm. 179, noviembre de 1903, 144.

Luis de Cuenca, Carlos. "Nuestros grabados". La Ilustración Española y Americana, año XlıV, núm. XLII, 15 de noviembre de 1900, 279-282.

Mac Gregor, Josefina. "México y España: de la representación diplomática oficial a los agentes confidenciales, 1910-1915”. Historia Mexicana, año L, L(2) (octubre-diciembre 2000): 309-330. . México y España: del Porfiriato a la Revolución. México: Instituto Nacional de Estudios Históricos de la Revolución Mexicana, Secretaría de Gobernación, 1992.

Martín Mínguez, Bernardino. "Congreso iberoamericano. Discurso de don Justo Sierra”. El Día, año xxi, núm. 7259, 12 de noviembre de 1900, 1.

Minimus. "Sección de polémica". La Lectura Dominical, año viI, núm. 359, 18 de noviembre de 1900, 728.

Moya López, Laura A. "México: su evolución social. 1900-1902. Aspectos teóricos fundamentales”. Sociológica año 14(41) (septiembre-diciembre de 1999): 127-156.

Nervo, Amado. Obras completas. Tomo i. Edición, estudios y notas de Francisco González Guerrero (prosas) y Alfonso Méndez Plancarte (poesías). Madrid: Aguilar, 1967.

"Lo de Puebla". La Correspondencia de España, año LXI, núm. 19,276, 21 de noviembre de 1910, 5.

. "Gentes y cosas de México. México nuevo". La Ilustración Artística, año xxII, núm. 1,108, 23 de marzo de 1903, 200-206. 
. "Gentes y cosas de México. Justo Sierra”, La Ilustración Artística, año XXI, núm. 1087, 27 de octubre de 1902, 6.

Peludo Gómez, María del Rosario. "Enemigos de la patria y guerras inevitables: el discurso de la identidad nacional en México y España (siglo XIX). En Encuentro de Latinoamericanistas Españoles. s. l. España: СЕеıв, 2006, 1,062-1,078.

Pérez de Guzmán, Juan. "El Ateneo Científico-Literario de México". La Ilustración Española y Americana, año XLVI, núm. XXIII, 22 de julio de 1901, 390-391.

Rivero, Nicolás. Recuerdos de México, 1910. Habana: Imprenta y papelería de Rambla y Bouza, 1911.

Sánchez Azcona, Juan. "El ministro de México en Europa expone a los lectores de El Liberal la verdadera situación de su país”. El Liberal, año xxxvin, núm. 18,612, 16 de noviembre de 1910, 1.

Sánchez Andrés, Agustín y Juan Carlos Pereira Castañares, coords. España y México. Doscientos años de relaciones 1810-2010. México: Universidad Nacional Autónoma de México, Universidad Michoacana de San Nicolás de Hidalgo, Comisión Española de Historia de las Relaciones Internacionales, 2010.

Sánchez Andres, Agustín y Raul Figueroa Esquer, coords. México y España en el siglo XIX. Diplomacia, relaciones triangulares e imaginarios sociales. México: Universidad Michoacana de San Nicolás de Hidalgo, Instituto de Investigaciones Históricas, Instituto Tecnológico Autónomo de México, 2003.

Sierra, Justo. Obras completas del maestro Justo Sierra. Discursos. Obras completas del maestro Justo Sierra. Tomo V. Discursos. Edición preparada por Manuel Maestre Ghigliazza. Revisada y ordenada por Agustín Yáñez. México: Universidad Nacional Autónoma de México, Coordinación de Humanidades, 1948.

Sesto, Julio. “CCómo está México?”. Nuevo Mundo, año xviıI, núm. 919, 17 de agosto de 1911, 3.

Sux, Alejandro. La juventud intelectual de la América hispana. Buenos Aires: Tipografía el anuario de la exportación, 1911.

Sin firma. "Altamira en México". Actualidades, año III, núm. 107, 3 de marzo de 1910, 1. 
Sin firma. "Noticias". La Correspondencia de España, año LI, núm. 15,635, 25 de noviembre de 1900, 4.

Sin firma. "Noticias americanas". La Época, año LII, núm. 18,097, 27 de octubre de 1900, 2.

Sin firma. "Notas políticas". La Época, año LXII, núm. 21,420, 11 de junio de 1910, 3.

Sin firma. "Congreso hispanoamericano. La sesión inaugural”. La Época, año LII, núm. 18,112, 11 de noviembre de 1900, 1.

Sin firma. "Congreso Hispano-Americano". El Globo, año XXVI, núm. 9,107, 10 de noviembre de 1900, 1.

Sin firma. "Fraternidad". El Globo, año xxvı, núm. 9,107, 10 de noviembre de 1900, 1.

Sin firma. "La situación de México". El Liberal, año xxxix, núm. 13,568, 7 de enero de 1911, 1.

Sin firma. "Congreso Ibero-Americano". Nuevo Mundo, año viı, núm. 359, 21 de noviembre de 1900, 8 y 9.

Tenorio Trillo, Mauricio. Artilugio de la nación moderna: México en las exposiciones universales, 1880-1930. México: Fondo de Cultura Económica, 1998. 